\title{
As controvertidas minas de São Paulo (1550-1650)*
}

\section{The controversial mines of São Paulo (1550-1650)}

\author{
JOSÉ CARLOS VILARDAGA** \\ Departamento de História \\ Universidade Estadual de Londrina \\ Londrina (PR) \\ Brasil
}

RESUMO Célebres descobridores de minas de ouro nas Minas Gerais e nas de Goiás - entre fins do século XVII e o século XVIII -, os moradores da Capitania de São Vicente, especialmente os da vila de São Paulo, tiveram ações nebulosas quanto às supostas riquezas minerais de seu próprio solo. A existência de minas na capitania nos séculos XVI e XVII sempre foi um assunto controvertido, tanto em seu tempo, quanto para a historiografia. Superestimadas por alguns ou menosprezadas por outros, as verdadeiras dimensões dessa riqueza se perderam no emaranhado de interesses que a envolvia. Aqui, pretendemos apresentar alguns indícios desta riqueza mineral, bem como parte dos interesses ambíguos em relação às minas de São Paulo nesse tempo, em especial quando da presença na vila do governador geral do Brasil, D. Francisco de Souza.

* Artigo recebido em: 04/10/2012. Aprovado em: 12/08/2013.

** Doutor em História Social pela Universidade de São Paulo. Professor na Universidade Estadual de Londrina Contato: zecavilardaga@gmail.com 
Palavras-chave minas de ouro, São Paulo colonial, Francisco de Souza

ABSTRACT Famous discoverers of gold mines in Minas Gerais and Goiás - between the late seventeenth century and the eighteenth century -, the residents of Capitania of São Vicente, especially the village of São Paulo, had nebulous actions regarding his supposed mineral wealth on their own soil. The existence of mines in the captaincy in the sixteenth and seventeenth centuries has always been a controversial subject, as in its time as to the historiography. Overestimated by some or underestimated by others, the true dimensions of this wealth was lost in the tangle of interests that surrounded her. Here, we intend to present some evidence of this mineral wealth, as well as part of the ambiguous interests regarding the mines of São Paulo at this time, especially when the presence in the village of governor general of Brazil, D. Francisco de Souza.

Keywords gold mines, São Paulo colonial, Francisco de Souza

\section{Introdução}

$\mathrm{Na}$ alvorada do século XVII, entre os anos de 1600 e 1601, uma petição feita pelo recém-nomeado governador de Angola, João Fernandes Coutinho, circulou junto ao Conselho de Portugal, em Madrid. Diante deste documento, antevemos um governador que se dispõe a empreender grandes esforços e "tomar a si a conquista das minas de prata que há no dito reino". Para tanto, se oferecia a levar, por sua conta e risco, no primeiro ano, mil homens, sendo seiscentos deles de Portugal e quatrocentos do Brasil. Comprometia-se, ainda, nos dois anos seguintes, a custear mais mil homens "de pé e 60 cavalos". Com esses recursos, exploraria as minas chamadas de Cambambi e faria nele um forte. Em troca, pedia um contrato de nove anos. No parecer final, favorável, se falava do notável benefício que tal conquista traria e ainda se louvava a experiência de Coutinho naquelas terras. Ao final, uma pequena queixa: a de que fazia "anos que se trata da conquista das ditas minas e se tem feito muita despesa nisso com pouco fruto (...) e que não vem a Portugal hum só real do rendimento de Angola, por todo se consumir lá e no Brasil". ${ }^{1}$

Ao que parece, petições sobre exploração mineral em espaços coloniais eram bem recebidos junto ao Conselho de Portugal. Por essa época, o neto de Caramuru, Belchior Dias Moreia, andava por Espanha a solicitar a herança das vastas mercês de Gabriel Soares de Souza, que falecera em 1592, durante suas demandas minerais pelo São Francisco. Belchior

1 Archivo General de Simancas (AGS). Secretarias Provinciais, Libro 1461, docs. 10 e 11. 
prometia riquezas sem fim nas bandas de Sergipe del Rey, mas teria seus pedidos condicionados à apresentação efetiva da riqueza prometida. Nestes mesmos anos, o governador geral do Brasil D. Francisco de Souza já se instalara, com toda sua comitiva e aparato, na pequena vila de São Paulo de Piratininga em busca da confirmação dos indícios de riqueza mineral que chegavam até seus ouvidos. Vinha, ainda, ele sim, como herdeiro direto das mercês conseguidas por Gabriel Soares de Souza. Estas abriam um precedente cobiçoso a futuros postulantes de descobertas minerais, já que vislumbravam o direito de conceder sesmarias e lotes de minas, administração de mão de obra indígena, concessão de hábitos e títulos nobiliárquicos, comutação de degredos e até mesmo a criação de povoados. ${ }^{2}$ Um prato cheio!

D. Francisco de Souza conseguiria, ao longo da última década do século XVI e da primeira do século XVII, manter acesa, nas imaginações da Corte espanhola, a chama da sonhada riqueza mineral em territórios da América portuguesa, há duas décadas incorporados ao patrimônio da monarquia dos Habsburgos e, por conseguinte, à coroa espanhola.

Essa riqueza mineral, muitas vezes vista como quimera, fomentou uma imagem de certa irresponsabilidade do governador geral do Brasil, pois este abandonara as cada vez mais ricas regiões açucareiras do Nordeste, ainda vulneráveis aos assédios de outras potências europeias, em detrimento de uma especulada fortuna mineral. Os governadores gerais subsequentes, em especial Diogo Botelho e Diogo de Meneses, fariam questão de ressaltar tal atitude. Mas não foram os únicos. O sentido um tanto "quixotesco" das buscas minerais deste governador, vistas sempre em sentido retrospectivo, também foram assinaladas por historiadores de diversas tendências. ${ }^{3}$ Teremos oportunidade de problematizar um pouco mais o "sucesso" ou "fracasso" das iniciativas do governador Francisco de Souza, mas devemos tomar como base a simultaneidade das iniciativas minerais apontadas acima. Longe de serem frutos isolados de algum voluntarismo ambicioso, estes pedidos e ações se enquadravam perfeitamente nos projetos e perspectivas acalentadas pela monarquia filipina, apossada da coroa portuguesa e seus domínios desde 1580.

Souza, no Brasil, e Coutinho, em Angola, não eram sonhadores solitários, nem abnegados aventureiros dispostos a perder suas fortunas em busca de sonhos improváveis. Estavam, sim, mais para autoridades que viram uma oportunidade na conjunção de interesses entre as demandas da monarquia, e seus próprios projetos e perspectivas pessoais. Alimentar o

AGS. Secretarias Provinciais, Libro 1466, fls.288-290

3 A visão quixotesca sobre Francisco de Souza, alcunhado em sua própria época, conforme Frei Vicente de Salvador, de Francisco "das Manhas", está presente de Varnhagen a Sérgio Buarque de Holanda. De modo geral, a historiografia paulista o enxerga como alguém que "atirou no que viu e acertou no que não viu", pois resultara de suas frustradas iniciativas minerais a paternidade bem sucedida das bandeiras. 
sonho da descoberta mineral, que tanto acalentava os ouvidos da realeza na Península Ibérica, foi, muitas vezes, uma iniciativa deliberada. Lembremos novamente de Gabriel Soares que, em busca de mercês, produzira um livro dedicado a Felipe II de Espanha (I de Portugal), propagandeando as riquezas minerais das possessões portuguesas na América. ${ }^{4}$

A monarquia de que falamos aqui, tão aberta e suscetível aos apelos minerais, era, nessa altura, uma grande conjunção jurisdicional. Sob o manto da monarquia Habsburgo, liderada naquele momento por Felipe III, a Coroa portuguesa e suas possessões coloniais foram incorporadas ao patrimônio daquela dinastia após a malfadada campanha cruzadística em Álcacer-Quibir, levada a cabo pelo casto rei Sebastião, e que resultara num reino sem rei, e sem herdeiros diretos, em 1578. Dois anos depois, em 1580, se conformava a União das Coroas Ibéricas, costurada pelo Acordo de Tomar que, teoricamente, garantiria alto grau de autonomia ao reino português. Naquela ocasião, Felipe II de Espanha, neto por linha materna de D. Manuel, o Venturoso, fazia impor sua "herança" sobre a coroa portuguesa. ${ }^{5}$ A continuidade cultural, econômica e nobiliárquica entre os dois reinos, o entrecruzamento de interesses comerciais inclusive em esferas coloniais, bem como o afamado centralismo da monarquia dos felipes, bem demonstram que a autonomia de Portugal foi, em verdade, letra morta. ${ }^{6} \mathrm{O}$ vice-rei, nomeado e atrelado aos interesses dos reis de Castela, em Madrid, ainda governava o reino português secundando pelo Conselho de Portugal, alocado na corte espanhola. As decisões passavam, necessariamente, pela chancelaria real e as políticas traçadas na Corte obedeciam a estratégias e interesses imperiais da monarquia Habsburgo.

Este império, custoso, pesado, envolvido em inúmeras questões europeias, demandava riqueza. A prata de Potosí, no baixo Peru, sustentava já há algumas décadas parte desse peso. E, em verdade, "novas Potosís" nunca saíram do horizonte de expectativas imperiais. Ao herdarem as terras

4 No primeiro capítulo de seu livro, Ronald Raminelli promove uma interessante discussão sobre este sentido propagandístico da obra de Gabriel Soares e como ela entrava no circuito de pedidos de mercês; RAMINELLI, Ronald. Viagens ultramarinas: monarcas, vassalos e governo a distância. São Paulo: Alameda, 2008.

5 A frase clássica, que teria sido proferida por Felipe II a respeito de sua coroação como rei de Portugal, "yo lo heredé, yo lo compre, yo lo conquiste", ainda causa controvérsia quanto ao peso de cada um destes recursos utilizados pelo monarca castelhano. Bouza Alvares coloca mais ênfase na compra e negociação; e Rafael Valladares, recentemente, reforçou o peso da conquista militar. VALLADARES, Rafael. La conquista de Lisboa: violencia militar y comunidad política en Portugal, 1578-1583. Madrid: Marcial Pons, 2008; BOUZA ÁLVAREZ, Fernando. Portugal no tempo dos Filipes: política, cultura, representações (1580-1668). Lisboa: Edições Cosmos. 2000.

6 As continuidades têm prevalecido sobre as "fraturas", nas análises sobre as relações entre os reinos de Portugal e Espanha durante o período da União Ibérica (1580-1640). Os trabalhos mais recentes tentam superar uma visão marcadamente nacionalista, e caminham na contramão de um olhar sobre a União Ibérica, enviesado pelo olhar retrospectivo da chamada "Restauração". Dentre alguns trabalhos que discutem essa continuidade: SCHAUB, Jean Frederic. Portugal na Monarquia Hispânica (1580-1640). Lisboa: Livros do Horizonte, 2001; BOUZA ÁLVARES, Fernando. Portugal no tempo dos Filipes; CURTO, Diogo Ramada. O discurso político em Portugal (1600-1650). Lisboa: Centro de Estudos de História e Cultura Portuguesa, 1988; OLIVEIRA, Antônio. Poder e oposição política em Portugal no período filipino, 1580-1640. Lisboa: Difel, 1990; VALLADARES, Rafael. Portugal y la Monarquia Hispânica, 1580-1668. Madri: Arco/Libros, 2000; OLIVAL, Fernanda. Felipe II. Lisboa: Temas \& Debates, 2008; CASALILLA, Bartolomé Yun (dir.). Las redes del Imperio: élites sociales en la articulación de la Monarquia Hispánica. Madrid: Marcial Pons Historia/Universidad Pablo de Olavide, 2009. 
portuguesas, a monarquia castelhana herdava também novas possibilidades de pesquisa mineral, novas promessas e também velhas expectativas, já que no reino português sonhava-se, assim como em Espanha, há décadas, no encontro de ricas minas. Sérgio Buarque de Holanda ressaltou o grau de inconformismo português com a inexistência de uma "Potosí" em terras pertencentes ao mundo luso. ${ }^{7}$

O império português herdado, ou que se fez herdar, incluía feitorias ao longo do Oceano Índico e do litoral africano, ilhas no Atlântico e domínios na América, e se somava ao império que Felipe II, por sua vez, havia herdado de seu pai, o imperador Carlos V, em 1556. ${ }^{8}$ Este último incluía Castela, Aragão, Nápoles, Milão, os Países Baixos, a Franche-Comté e as possessões americanas. Era um império "cuya vastedad provocaba la admiración y el asombro, era el mayor jamás conocido en la historia. Era, como escribió con orgullo un español, 'mas de veinte veces mayor que lo fue el Romano'". ${ }^{9}$

Portanto, a união das coroas articulou um amplo espaço imperial numa verdadeira monarquia universal, e alargou enormemente os espaços e as possibilidades de conexões, intercâmbios e explorações. ${ }^{10} \mathrm{~A}$ conjunção das expectativas minerais monárquicas, com a ânsia de um bom punhado de aventureiros dispostos a singrar territórios em busca de ouro, prata e outras preciosidades, formou o caldo ideal para a distribuição de mercês e estímulos para estas iniciativas. A promessa de riqueza mineral, sua demanda e posterior beneficiamento, alimentava uma parte importante desta "economia das mercês". E as promessas não eram poucas. Como exemplo primordial, lembremos que Gabriel Soares de Souza ganharia, em caso de sucesso, o restrito e excepcional direito de usar o título de marquês, até então concedido pela coroa espanhola a personagens como Hernán Cortez e Francisco Pizarro.

Um destes espaços privilegiados de encontro entre as expectativas monárquicas e alguns personagens em demandas por riquezas e mercês foi a capitania de São Vicente, em especial a região da vila de São Paulo de Piratininga e suas redondezas. Estas promessas mobilizaram algumas iniciativas isoladas ao longo da segunda metade do século XVI, atraíram o governador geral do Brasil entre 1599 e 1611 e ainda despertariam muitas dúvidas, desconfianças e mercês ao longo do século XVII, em especial durante sua primeira metade.

7 HOLANDA, Sérgio Buarque de. A mineração: antecedentes luso-brasileiros. In: História Geral da Civilização Brasileira. Tomo I, Livro II. São Paulo: Difel, 1968, p.228-258.

8 Na altura que Felipe II incorpora Portugal, as possessões deste último incluem, dentre outras: Ceuta, no norte da África; ilha da Madeira, arquipélago dos Açores, Cabo Verde e ilha de São Tomé e Príncipe, no Atlântico; enclaves e feitorias na Costa do Ouro, Senegâmbia e Angola, na África ocidental; e Moçambique na África Oriental. No Oriente, em torno de Goa, centro do Estado da Índia, os enclaves de Macau, Málaca, Ormuz e Timor.

9 KAMEN, Henry. Felipe de España. Madrid: Siglo Veintiuno de España Editores, 1997, p.257.

10 GRUZINSKI, Serge. Mondes meles de la Monachie catholique et autres 'connected histories'. Annales. Histoire, Sciences Sociales, 56 Année; n.1, p.85-117, Janvier-Février 2001. (Este último publicado em português na revista Topoi, Rio de Janeiro, mar de 2001, p.175-195) 


\section{Sondáveis interesses}

Afonso Sardinha, o moço, residia junto ao rio Pinheiros, em São Paulo e minerava em Jaraguá. Descobriu minas de ferro em Araçoiaba em 1589 e, com seu parceiro, Clemente Alvares, minas de ouro no Jaraguá, Vuturuna (Parnaíba) e Jaguamimbaba (nas proximidades da Serra da Mantiqueira). Sardinha ainda teria construído dois engenhos para fundição de ferro em Araçoiaba, sendo um deles doado ao governador geral do Brasil, D. Francisco de Souza, instalado em São Paulo desde 1599. ${ }^{11}$ O moço faleceu em 1604, em pleno sertão, e fez correr fama de que deixara em testamento "oitenta mil cruzados de ouro em pó enterrado num botelho de barro" A afirmação foi ironizada por Afonso Taunay, pois segundo ele, depois da conversão aproximada desta quantidade em quilos, Sardinha o moço poderia ser considerado um "Fugger brasileiro". ${ }^{12}$ Esta suspeitosa riqueza de Sardinha pode ser considerado apenas mais um dos episódios nebulosos que envolvem o tema das minas na São Paulo dos séculos XVI e XVII.

Algumas décadas depois, e após muitas especulações, pedidos e expectativas, as minas de São Paulo ainda pareciam despertar dúvidas. Numa carta de Salvador Correia de Sá e Benevides ao rei, datada de 1654, este falava que, em relação às minas da Capitania de São Vicente, os interessados "as avaliam por mais do que são; e os outros por menos do que mostram". ${ }^{13}$ Fazia questão de pontuar que "depois de todas aquelas diligencias feitas com Dom Francisco de Sousa por el rey de Castela e das noticias das particularidades (...) não acabo de persuadir me a que na realidade aja tais minas". Por fim, recomendava cautela para não alimentar muitas ambições e solicitava o envio de alguém com desinteresse para as demandas minerais, segundo ele, coisa "difícil de conservar entre ouro e prata em terras tão remotas", ainda mais com "os ânimos daqueles moradores sediciosos e turbulentos; porque é a Rochela do sul a capitania de São Paulo". Reconhecia que ia contra a opinião de muitos, mas, assim mesmo, acreditava que valeria a pena o esforço.

E o esforço da família Sá em relação às tais minas de São Paulo não era novo. Anthony Knivet já havia relatado como participara de uma entrada liderada pelo pai de Benevides, Martim de Sá, em 1599. ${ }^{14}$ Ademais, o avô, Salvador Correia de Sá, era próximo do governador D. Francisco e herdou

11 D. Francisco de Souza, sétimo governador geral do Brasil, o terceiro nomeado no contexto da União das Coroas Ibéricas, tomou posse em Salvador no ano de 1591. Desde o início do seu governo, a preocupação mineral se fez evidente, tanto que ele foi o grande apoiador de Gabriel Soares de Souza em suas investidas no São Francisco. A partir de 1595, o governador voltou os olhos para São Paulo, de onde chegavam notícias esperançosas. Em 1599, ele resolveu conferir pessoalmente as tais informações e se transferiu para a pequena vila vicentina, onde permaneceu até 1604 (em 1602 seu mandato como governador se encerrara). Souza ainda voltou a São Paulo como governador das Capitanias da Repartição Sul e Superintendente das Minas em 1609 e na mesma vila miúda morreu em 1611.

12 TAUNAY, Afonso d'Escragnolle. Historia geral das bandeiras paulistas. v.V. São Paulo: Typ.Ideal, 1929.

13 Biblioteca Pública Municipal de Évora (BPME), Códice CXVI, Doc3. Carta de 02/09/1654.

14 KNIVET, Anthony. As incríveis aventuras e estranhos infortúnios de Anthony Knivet. Rio de Janeiro: Jorge Zahar Editor, 2007. 
as suas mercês após a sua morte, depois de algumas diligências políticas na corte de Madri. ${ }^{15}$ Em 1613, Salvador Correia de Sá recebeu as mercês, repassando-as, primeiro, para um dos filhos, Martim de Sá, e, depois, para o outro, Gonçalo de Sá. Segundo Carvalho Franco, Benevides viera de Portugal com o avô e o teria acompanhado a São Paulo, onde ficou parte de sua adolescência, por cerca de cinco anos, fazendo ensaios de metal e recolhendo notícias sobre as tais riquezas minerais. Numa carta do avô de 1616, citada por Carvalho Franco, Salvador Correia alegou que estava averiguando as minas e que havia muito ouro, que a cada dia se descobria mais, mas que os ministros reais teriam empenho em esconder as descobertas, já que atingiam suas jurisdições. ${ }^{16}$ De fato, Salvador Correia chegou a encarregar o filho Gonçalo de empreender uma devassa na vila para apurar a suspeita de que moradores estavam induzindo testemunhas a relatar que não havia ouro algum. ${ }^{17}$

As notícias das riquezas sempre se revelaram desencontradas. As suspeitas variavam entre a ideia de riquezas minerais extremadas, desviadas, e a de inexistência de metal, tratando-se de um mito alimentado pelos moradores para arrancar privilégios da Coroa. Seja como for, sobre essa riqueza mineral, da qual Taunay, concordando com Capistrano de Abreu, chegou a afirmar que "muito ogó haveria", sempre recaiu certa suspeita de traquinagem e malícia por parte dos paulistas, tanto na perspectiva do desvio quanto na da inexistência. Uma população mancomunada para ludibriar autoridades e fiscais, como vislumbrou Gonçalo de Sá. ${ }^{18}$

As eternas suspeitas e boataria em torno das minas esgotaram a paciência até mesmo dos membros do Conselho de Portugal. Em 1630, diante de uma nova petição sobre as minas, feita por Martim de Sá, seus membros responderam que D. Francisco de Souza "não fez cousa de consideração nem de que resultasse utilidade" e Salvador Correia de Sá "também não fez nada nem apurado com clareza a importância delas". Portanto, se não era possível "alcançar a verdade e certeza das minas de ouro do Brasil", melhor negar novas mercês e deixar que os particulares buscassem livremente o ouro, desde que pagassem o quinto. Neste mesmo ano, o tema parece ter voltado com força, já que o vigário Lourenço de Mendonça, que viera de Potosí - e segundo seu memorial "persona mais inteligente em matéria de minas" - também solicitava a mercê para explorar e beneficiar as minas de São Paulo, tudo sob suas custas. Em sua petição, usou um argumento técnico para justificar porque D. Francisco de Souza fracassara e como isso não se repetiria:

15 AGS. Secretarias Provinciais, Libro 1506

16 FRANCO, Francisco de Carvalho. História das minas de São Paulo: administradores gerais e provedores (séculos XVI e XVII). São Paulo: Conselho Est. de Cultura de São Paulo, 1964

17 Instituto Nacional da Torre do Tombo (INTT). Papéis do Brasil, Códice 10, MF695, f.151.

18 TAUNAY, Afonso. Historia Geral das bandeiras paulistas, v.5, p.141. 
Fue pues el dito Dom Francisco a beneficiar las dichas minas y sierras por lavadores y bateas o artesones por el qual modo solamente se cava el oro graúdo y que la vista llega a alcançar y se pierde la maior cantidad que es el menudo y que esta encorporado por la tierra y piedra como es el de las minas de Sarruma del Peru.

Para superar o problema, dizia o padre que adotaria o sistema de azougue - uso do mercúrio - utilizado no Peru, e que as minas renderiam mais que as de Potosí. Prometia ainda remediar a monarquia com muitos bens e fazer entrar em Lisboa a mesma riqueza que entrava em Castela. Para seu benefício, pedia somente que pudesse trazer para São Paulo gente de Potosí que soubesse beneficiar o ouro e gente para construir engenhos. Por fim, pedia provisões para os capitães e "justicia" de São Paulo, ordenando que ninguém o impedisse, pois soubera que "algunas veces ho an hecho a hombres que a esto venieron del Peru". ${ }^{19}$ Lourenço deixa transparecer que existiria uma grande riqueza mineral, não só mal trabalhada, pela exploração na base da faiscagem, como atravancada pelas autoridades, ou seja, um discurso muito semelhante ao de Salvador Correia de Sá anos antes.

Outro documento célebre é a carta de Manuel Juan Morales ao rei, de 1636. Ele relata sua permanência em São Paulo desde pelo menos 1595, e sua carta cumpre bem o papel de denunciar uma série de descalabros, justificando mercês ao próprio missivista, detentor da solução de uma parte dos problemas. O tema dos metais de São Paulo perpassa seu relato, já que o autor era especialista em minério de ferro. Em relação ao ouro, alardeia que quando foi responsável pela arrecadação dos quintos, fez subir de setenta mil maravedis, em 1603, "hasta el dia de oi, que es de 636, a cantidad de três mil y seiscentos cruzados". ${ }^{20}$ Queixava-se, contudo, que as autoridades enviadas a São Paulo para coibir abusos, principalmente relacionados ao apresamento de gentios no sertão e aos ataques às reduções jesuíticas, eram subornadas com ouro.

Em 1609, o capitão-mor Gonçalo Conqueiro foi destituído do posto e enviado preso à Bahia pelo governador Diogo de Meneses, sob a suspeita de que ele havia escondido ouro não quintado em sua casa. ${ }^{21}$ Autoridades corrompidas pelo ouro, ciosas de seu poder e abrigadas por uma população turbulenta e insubmissa que praticava toda sorte de impedimentos, roubos e boicotes deitaria frutos no tempo. Já no final do século XVII, em 1692, o governador do Rio de Janeiro, Antonio Paes de Sande, dizia que os paulistas escondiam as verdadeiras informações das minas e teriam

19 Biblioteca Nacional do Rio de Janeiro (BNRJ), Coleção Castelo Melhor, 07,03,003. Doc.17.

20 CORTESÃO, Jaime (org.). Jesuítas e bandeirantes no Guairá. Rio de Janeiro: Biblioteca Nacional, Divisão de Obras Raras, 1951.

21 Registro Geral da Câmara Municipal de São Paulo (RGCSP), 1583-1636, vol. 1, São Paulo: Typographia Piratininga, 1917, 03/03/1609. 
sido, inclusive, indiretamente responsáveis pela morte do governador D. Francisco de Souza, que se deu em São Paulo em 1611, já que este teria morrido de desgosto depois das notícias do assassinato de um mineiro que enviara às minas. ${ }^{22}$

Fossem por iniciativa de alguns indivíduos ou de uma população supostamente irmanada e unida em torno da proteção e disfarce das ditas minas, a visão que parece prevalecer neste século XVII é a de que as riquezas minerais de São Paulo eram reais, mas sempre ludibriadas ou erroneamente beneficiadas pelos paulistas. Por outro lado, não se pode deixar de estranhar as recorrentes investidas da poderosa família Sá em torno das minas e de suas mercês. Além disso, como justificar a longa permanência do governador geral do Brasil motivada por elas? Estes supostos empecilhos colocados pelos moradores de São Paulo poderiam ser parte de uma retórica. O discurso sobre um povo sonegador, que colocava obstáculos ao acesso mineral, bem poderia servir para manter em suspensão as possibilidades minerais, valorizar o esforço, e para mais delas se extrair privilégios. De todo modo, os vínculos entre a riqueza mineral e os privilégios jurisdicionais nos parecem claros. O quanto um servia para justificar o outro é uma questão ainda em aberto.

\section{Insondáveis minas}

Independente destas visões suspeitosas, o que podemos aferir sobre a existência efetiva de ouro em São Paulo? A crença de que a Capitania de São Vicente encerrava, em suas entranhas, múltiplas e abundantes riquezas minerais era bem antiga. Uma das primeiras notícias sobre a existência destas riquezas se deu através de uma carta do bispo Pedro Fernandes Sardinha ao rei, em 1552, comunicando a chegada de um navio que, vindo de São Vicente, trazia a nova de que "era muito ouro achado pela terra dentro". ${ }^{23} \mathrm{O}$ interior desconhecido da América meridional, que incluía a região dos rios Paraná e Paraguai, por sua vez, era alvo de notícias de riqueza desde a terceira década do século XVI, como comprovam as cartas de Diego Garcia, em 1526, Sebastião Caboto, Pero Lopes de Souza e do próprio Cabeza de Vaca. ${ }^{24}$ Os padres jesuítas estacionados no planalto de Piratininga também noticiavam tais possibilidades. Segundo Nóbrega, uma

22 O trecho do relatório de Sande que apresenta tais suspeitas está em FRANCO, Francisco de Assis Carvalho. Dicionário de bandeirantes e sertanistas do Brasil, séculos XVI, XVII, XVIII. São Paulo: Comissão do IV Cent. da Cidade de São Paulo, 1954. A versão de que Francisco de Souza morreu de desgosto prevaleceu no tempo. Num documento espanhol se fala da morte do governador depois que o tal mineiro morreu, a mando dos jesuítas: Libro de los sucessos del ano de 1624, Biblioteca Nacional de España (BNE), MSS2355. Esse mineiro, nunca nomeado, parece ter vindo com Francisco de Souza em 1608 e foi instruído pelo Conselho da Índia, conforme solicitação do rei ao vice-rei de Portugal. Biblioteca D’Ajuda. Códice 51-VIII-18.

23 CARVALHO FRANCO, Francisco de Assis. História das minas de São Paulo, p10.

24 MAFFEI, Lucy; NOGUEIRA, Arlinda Rocha. O ouro na capitania de São Vicente nos séculos XVI e XVII. Anais do Museu Paulista, São Paulo, v.20, p.7-135, 1966. 
das razões para que Tomé de Souza mandasse fechar o caminho rumo ao Paraguai era o fato da região ter muito ouro e prata. ${ }^{25} \mathrm{Com}$ efeito, em 1559 a rainha regente D. Catarina comunicava ao governador Mem de Sá que enviara o mineiro Luis Martins para averiguar as notícias das minas na capitania de São Vicente. ${ }^{26}$ Teria acompanhado o mineiro o capitão-mor Brás Cubas que, conforme carta depois enviada ao governador, dizia ter encontrado algum ouro cerca de 30 léguas de Santos. Afirmava ainda que o mineiro havia entrado mais uma vez na região e, sozinho, localizara seis outros locais com ouro. ${ }^{27}$ Esta entrada do prático em mineração Martins teria percorrido as redondezas de São Paulo, recolhendo algum ouro e pedras verdes, de pouca monta e interesse, na região de Jaraguá e Caatiba. ${ }^{28}$ Mais tarde, em 1585, uma entrada de Jerônimo Leitão ao Paranaguá teria trazido algum ouro de lavagem. ${ }^{29}$

De qualquer maneira, as suspeitas sobre a existência de metais preciosos na Capitania obedeciam a algumas informações concretas e outras tantas marcadas por expectativas e desejos. ${ }^{30}$ Além das tais amostras encontradas e remetidas desde a década de 1550, as lendas de origem tupiniquim sobre o Itaberaba-açu - a Serra do Sabarabuçu -, ou "montanha resplandecente", alimentavam a imagem deste interior meio mítico, como que guardando um novo Potosí. Sem contar a no mínimo curiosa "philosofia" da época que também contribuía para aumentar tais expectativas. Embora um pouco mais tardio - do começo dos seiscentos -, encontramos um exemplo dela em um documento da Biblioteca D'Ajuda, cujo título é "Relações das capitanias do Brasil". Na parte sobre a capitania de São Vicente, lê-se:

Nos limites desta capitania pela terra adentro obra de quarenta léguas estão as minas de ouro e prata que Dom Francisco de Sousa diz ter descobertas, as quais muitos anos antes se tinha notícia e por boa razão de philosophia esta região do Brasil deve ter mais e melhores minas que as do Peru por ficar mais oriental que ela e mais disposta para a criação de metais. ${ }^{31}$

Nesta geografia, uma certa latitude ampliada - a mesma de Potosí seria, então, favorável à existência de metais, o que incluía a região do Paraguai, São Vicente e mesmo as áreas africanas de Angola e Moçambique,

25 CARVALHO FRANCO, Francisco. História das minas de São Paulo.

26 Documentos Interessantes, v.XLVIII. São Paulo: APESP, 1929, p.31.

27 MAFFEI, Lucy; NOGUEIRA, Arlinda Rocha. O ouro na capitania de São Vicente nos séculos XVI e XVII.

28 ELLIS, Miriam. As bandeiras na expansão geográfica do Brasil. In: HOLANDA, Sérgio Buarque (dir.). História geral da civilização brasileira. Tomo 1, v.1. São Paulo: Difel, 1972, p.273-296.

29 ELLIS, Miriam. Pesquisas sobre a existência do ouro e da prata no planalto paulista nos séculos XVI e XVII. Revista de História, São Paulo, ano 1, n.1, p.51-71, jan./mar. 1950.

30 Sobre amostras e notícias de riquezas minerais na capitania desde meados do século XVI, ver FRANCO, Francisco. História das minas de São Paulo; HOLANDA, Sérgio Buarque. A mineração: antecedentes luso-brasileiros; MAFFEI, Lucy de Abreu; NOGUEIRA, Arlinda Rocha. O ouro na capitania de São Vicente nos séculos XVI e XVII; ELLIS, Miriam. Pesquisas sobre a existência do ouro e da prata no planalto paulista nos séculos XVI e XVII.

31 Biblioteca D’Ajuda. Códice 51-IX-25, f.142 
do outro lado do oceano. De qualquer modo, as iniciativas de pesquisa mineral no Brasil são contemporâneas de outras investidas da mesma natureza em variadas partes, tanto da África quanto da América, tanto em áreas portuguesas quanto em áreas castelhanas. ${ }^{32} \mathrm{O}$ tema das riquezas minerais no Brasil, em especial em São Paulo, ganharia novo fôlego e impulso exatamente durante o período da União das Coroas Ibéricas, diante do ansioso e crescentemente endividado império dos felipes.

Os relatos do almirante Diego Flores de Valdés - enviado por Felipe II ao Atlântico Sul capitaneando uma multifuncional armada entre os anos de 1582 e 1584 -, asseguravam ao rei a existência de metais de prata (mais ricos que de Potosí), cobre e ouro na Capitania de São Vicente. Neles, o almirante asturiano ainda solicitava o envio urgente de mineiros para "labrar las minas (...) que ali ha y estan descubiertas". ${ }^{33} \mathrm{E}$ as notícias não pararam por aí. Em seu livro direcionado ao rei Felipe II, Gabriel Soares de Souza alertava sobre a capitania de São Vicente:

Não há dúvida se não que há nestas capitanias outra fruta melhor que é a prata, o que se não acaba de descobrir, por não ir a terra quem a saiba tirar das minas e fundir. ${ }^{34}$

Contudo, as maiores pistas sobre estes supostos minérios estão nos passos do governador geral, D. Francisco de Souza, em São Paulo. ${ }^{35}$ Sabemos que ele foi atraído à vila pelas notícias de certo ouro encontrado pelos Sardinha (o velho e o moço) nas cercanias da vila. ${ }^{36}$ Em novembro de 1598, na iminência da chegada de Souza, Afonso Sardinha, o moço, encontrava-se em pleno sertão acompanhado de "alguns mancebos e mais de cem índios cristãos" em demanda de ouro e outros metais. ${ }^{37}$ Foi justamente na experiência mineral desta família que D. Francisco se apoiou, reconhecendo, inclusive, sua precedência nas pesquisas minerais. Em 1601, o governador proibiu quem quer que fosse, exceto os Sardinha, de bulir nas

32 Vale aqui ressaltar que as iniciativas minerais no Brasil desde os anos de 1560 coincidem com notícias, expectativas e iniciativas levadas a cabo também nas "fantásticas" minas de Moçambique, controladas pelo reino de Monomotapa; em Cambembe (Angola); e mesmo na província do Guairá, no Paraguai. Portanto, as investidas minerais devem ser vistas em seu conjunto e, no contexto da união das coroas, sob uma mesma coordenação imperial.

33 Archivo General de Indias (AGI). "Advertencias de Diego Flores de Valdés ao Rey". Patronato, 33, n.3, R.4, f.1 e f.2.

34 SOUZA, Gabriel S. Tratado descritivo do Brasil em 1587. São Paulo/Brasília: Nacional, 1987, p.115.

35 Vale ressaltar que D. Francisco de Souza esteve sempre entre os apoiadores da causa filipina nas demandas pela Coroa de Portugal, e foi homem ligado a Cristóvão de Moura. Foi o terceiro governador geral nomeado no contexto da União das Coroas, e Taunay o chamava de "delegado e homem de confiança de Felipe II"; e mesmo Sérgio Buarque o chamava de homem dos felipes.

36 Carvalho Franco sugere que o verdadeiro imã teria sido algumas amostras levadas por um mameluco que, desdobrado de uma entrada liderada pelo capitão-mor João Pereira Botafogo, chegara até a Bahia. Esta versão é também difundida por Piso e Marcgrave, quando divulgaram os relatos de Willem Von Glimmer, mineiro flamengo inserido na bandeira de Botafogo. FRANCO, Francisco. Dicionário de bandeirantes e sertanistas do Brasil; PISO, Guilherne; MARCGRAVE, George. Historia Naturalis Brasiliae (1648). Disponível em: <http://biblio.etnolinguistica. org/marcgrave_1648 historia>. Acesso em: 10 set. 2012.

37 Actas da Câmara da Cidade de São Paulo. (ACVSP). Vol. I a V. 2 ed. São Paulo: Publicação da Divisão do Arquivo Histórico; Divisão do Arquivo Histórico do Departamento de Cultura, 1967. Vol II, 14/11/1598. 
minas, enquanto os mineiros que haviam sido solicitados não chegassem para avaliar as descobertas. ${ }^{38} \mathrm{As}$ reservas efetivamente exploradas foram de ouro - principalmente de faiscagem - e ferro. A prata, tão sonhada e sondada, aparentemente não foi descoberta em grandes quantidades, apesar de algumas notícias e certa boataria em contrário. ${ }^{39} \mathrm{~A}$ expedição de André Leão (1601), que possuía a declarada missão de buscar prata, parece ter apresentado, nesse quesito, resultados infrutíferos. Já o ferro de Biraçoiaba e o ouro de Jaraguá, Caativa, Vuturuna e Nossa Senhora de Monserrate são de quantidade de difícil aferição. Contudo, notícias esparsas, algumas pistas e informações denotam que houve algum ouro retirado das redondezas.

Os inventários mencionam pequenas quantidades relativas de ouro e prata, mas quase não há registro dos quintos efetivamente pagos, tirante as notícias de Morales em sua carta ao rei..$^{40}$ Uma das raras tentativas de quantificação ou aproximação do montante foi feita por Miriam Ellis. ${ }^{41} \mathrm{~A}$ autora contabiliza, em 470 inventários, do período de 1578 a 1700, pequenas parcelas de ouro e prata, totalizando cerca de 200 quilos de prata e 19 quilos de ouro, presentes, na sua maioria, em peças e ornamentos, como pratos, brincos, cruzes, taças, anéis etc. Eschwege teria indicado, segundo a própria Ellis, cerca de 930 arrobas (15.000 quilos), número que foi encampado por Roberto Simonsen em sua História Econômica do Brasil. Para Ellis, a prata viria inteiramente do Peru in natura ou em peças já trabalhadas; já o ouro teria procedências variadas, como da Guiné, em moedas e objetos do tempo da expedição de Martim Afonso, e algum ouro local, que era de tão pouca monta que não alteraria a dinâmica econômica da vila. De todo modo, reconhece a existência de ouro em São Paulo, pois atesta a tenda de ourives nos inventários de Maria Pedroso e Maria Gonçalves, esposas de Cláudio Furquim, contabilizando um pouco mais de um quilo de ouro em pó nos documentos. A princípio, parece negar a existência de alguma prata local. ${ }^{42}$

Em relação às minas existentes, além da mina do Jaraguá, de Afonso Sardinha, e Vuturuna, próxima a Santana de Parnaíba, existiam as chamadas "minas do Geraldo", no caminho para o morro do Jaraguá. Estas minas são comprovadas numa carta apócrifa, e sem data, inserida na publicação do

38 RGCSP, V.I, 19/07/1601.

39 Nos pedidos de mercês de Martim Rodrigues Godoy, mineiro de prata enviado à Espanha por Francisco de Souza em 1602, ele afirmava que seu desejo inicial era ir ao Peru, mas o governador o reteve e o mandou a São Paulo. Ali pesquisou e encontrou minas de ouro e "oito minas de prata", das quais levava algumas amostras. Outro mineiro, Azurara, falava de uma pedra que suspeitava ser prata e que fora deixada com Clemente Alvarez, em São Paulo. AGS. Secretarias Provinciales (SP), Libro 1463.

40 Em consulta do Conselho de Portugal sobre parecer dado por Francisco de Souza a uma petição feita por Diogo de Quadros, afirma-se que Quadros, durante todo o tempo em que esteve em São Paulo como provedor das minas, direcionou à casa de fundição apenas 500 cruzados, sendo enviados como quintos ao rei somente 100 . AGS. SP, 1463, v.157.

41 ELLIS, Miriam. Pesquisas sobre a existência do ouro e da prata no planalto paulista nos séculos XVI e XVII.

42 Inventários e Testamentos. Volume 5. São Paulo: Divisão do Arquivo do Estado de São Paulo, 1920. 
Livro Segundo do Governo do Brasil. ${ }^{43}$ O sujeito relatava, nesta carta, que, depois de quase ter sido preso por tentar averiguar os quintos na casa de fundição da vila, acabou sendo levado para ver amostras de ouro trazidas por Clemente Alvares. Este havia descoberto e fundido um ouro "mui finíssimo e limpo" que, segundo "Claudio" (talvez o ourives Claudio Furquim), tinha vantagem "do de Seraldo", na verdade Geraldo Correia Sardinha. Sabese que, natural de São Paulo, Clemente Alvares era homem empenhado e dedicado aos metais. Parceiro de Afonso Sardinha, o moço, durante suas empreitadas de pesquisa de minas, casou-se com a filha do castelhano Martim Rodrigues Tenório, um dos envolvidos no erguimento do engenho de ferro em Santo Amaro. Tornou-se, assim, cunhado do engenheiro flamengo Cornélio de Arzão, também envolvido, a partir de 1609, com a produção de ferro. Em 1600, ficou como guardião de certo metal que parecia prata, e foi responsável por fazer os testes adequados ${ }^{44}$ As Atas da Câmara denunciam sua presença no sertão, com sua tenda de ferreiro, resgatando com os índios em pelo menos duas ocasiões. ${ }^{45} \mathrm{Em} 1606$ - estimada data da carta apócrifa -, Clemente compareceu à Câmara de São Paulo para registrar algumas minas que tinha descoberto e, desse modo, não perder os direitos sobre elas, observando o que determinava o novo Regimento das Minas de São Paulo. ${ }^{46}$ É provavelmente deste ouro que nosso missivista em questão falava. Portanto, as notícias destas riquezas minerais são sempre inconclusivas. Continuamos, em termos de reais dimensões minerais, trafegando em terreno nebuloso.

\section{Governador, mineiros e ofícios}

Uma das primeiras medidas de Francisco de Souza, ainda em 1599, ao chegar a São Paulo, foi autorizar que todos pudessem tirar ouro, na tentativa de estimular os moradores envolvidos nas descobertas das minas. Mas, em 1601, dois anos depois, apesar de reforçar a autorização, o governador exigia o pagamento do quinto e proibia a circulação de ouro em pó, que deveria agora ser fundido; o que pode denotar a retirada e a circulação de certa quantidade deste tipo de ouro que escapava aos canais de fisco e regulação. ${ }^{47} \mathrm{Um}$ ano depois, o governador enviava a Espanha uma comitiva de mineiros e peritos para demandar mercês e alguns benefícios de exploração. A comitiva, dentre outras coisas, teria voltado com um Regimento das Minas, sobre o qual se referiu Clemente Alvares quando foi registrar suas descobertas na Câmara.

43 Livro Segundo do Governo do Brasil. Lisboa: CNDP, 2002, "Documento 116"; p.163.

44 AGS, Secretarias Provinciais. Libro 1463. Memorial de Manoel Pinheiro Azurara.

45 ACVSP, 31/10/1610

46 ACVSP, 16/12/1606

47 RGCSP, 27/05/1599. RGCSP, 11/02/1601. Em 1604 entrou em vigência o regimento das minas que apregoava a liberdade das minas, reforçada pelo Regimento de 1618. 
Esse regimento já causou certa dúvida na historiografia quanto à sua efetiva aplicação em São Paulo. Eschwege dizia que ele ficara perdido na Espanha por 50 anos, sendo de fato registrado em São Paulo e Rio de Janeiro apenas em 1652. ${ }^{48}$ Varnhagen, por outro lado, afirmava que ele havia sido registrado em Iguape já em 1605. Pela certidão apresentada por Manoel Pinheiro Azurara, mineiro-mor do Brasil, como peça de sua defesa num processo em Assunção, ficamos sabendo que ele comparecera à Câmara de São Paulo em julho de 1604 com suas provisões e Regimento que trazia do governador Diogo Botelho. Assim que chegou a São Paulo, teria começado a usar de seu ofício, e "mandou apregoar a liberdade das minas do ouro e que pagassem os quintos a sua majestade". Em agosto, acompanhado de padres jesuítas e do escrivão e tabelião público Belchior da Costa, foi às minas de Monteserrate e São Francisco, e lá fez a repartição das minas entre alguns moradores, e "senalou" as de Dom Francisco, naquele momento um morador "comum" da vila de São Paulo. Pinheiro teria voltado à vila e tentado, conforme seu regimento, arregimentar gentios para serem distribuídos nas minas, mas não foi bem-sucedido devido à "pouquidade do gentio". ${ }^{49}$ Para além deste regimento de 1603, foram feitos outro, em 1618, e mais um, em 1644. O de 1618, ainda no contexto da União das Coroas, fora elaborado especialmente para as "minas de São Paulo e São Vicente" e, ademais de reforçar a liberdade das minas, versava sobre a administração dos gentios, aldeados segundo a lei de 1611 e repartidos nas minas conforme algumas restrições. ${ }^{50}$

Estes regimentos só reforçam as expectativas e os investimentos feitos em torno das supostas minas. Taunay, baseado numa consulta de Salvador Correia de Sá e Benevides realizada pelo Conselho Ultramarino em 1677, afirma que o regimento de 1603 teria surgido em função das várias dúvidas existentes em relação às minas de São Paulo. Tal dúvida teria surgido depois das notícias da morte do mineiro alemão que andava com Francisco de Souza e dos boatos de que se fundia ouro do tamanho da "cabeça de um cavalo". ${ }^{51}$ Seja como for, o tal regimento teria sido trazido pela delegação que o governador mandara para a Espanha e que retornou à vila em 1604.

Esta delegação, que entre 1601 e 1602 esteve em Valladolid, onde estava instalada a corte de Felipe III, era formada pelos mineiros Diogo de Quadros, Manuel João (o Morales, da carta), Martim Rodrigues de Godoy

48 Informação de MAFFEI, Lucy de A; NOGUEIRA, Arlinda R. O ouro na Capitania de São Vicente nos séculos XVI e XVII.

49 Arquivo Nacional de Assunção (ANA). Civil e Criminal, 1549, 4, 1606

50 BNRJ. Coleção Castelo Melhor, 01,02,035, doc.17.

51 TAUNAY, Afonso. Historia Geral das bandeiras paulistas. Esta história do ouro do tamanho de uma cabeça de cavalo aparece no Libro de los sucessos del ano de 1624, alocado na BNE (MSS2355). Nele fala-se deste mineiro alemão que teria sido assassinado a mando dos jesuítas, que temiam que a notícia da riqueza aumentasse a servidão dos gentios. Conforme o manuscrito, o mineiro descobrira que poderia retirar "tan gran pedazo de oro como el cavallo en que estava", e tal noticia alarmara tanto os padres, que, na mesma noite, o mineiro foi encontrado morto. 
e Manoel Pinheiro (Azurara). Além das particulares demandas de mercês, eles levavam amostras das riquezas minerais de São Paulo; cartas com pedidos da Câmara da vila e a missão de organizar a extração de metal, o que incluía alguns pontos sensíveis, como a possibilidade de descer gentios, a cobrança de quintos e a fundição do metal. A comitiva tinha também a óbvia função de ganhar a simpatia do novo monarca - Felipe III - para as questões minerais vicentinas. ${ }^{52} \mathrm{~A}$ tarefa parece ter sido cumprida a contento e, deve-se ressaltar, o clima para tal era favorável.

Segundo Fernanda Olival, em análise sobre as influências do reinado de Felipe III sobre Portugal, o início do século XVII refletia uma aguda crise econômica que assolava todo o império, acumulada desde os tempos de Felipe II, e que obviamente ecoava forte no reino lusitano, que também tinha lá sua própria crise. Segundo ela, problemas agrícolas, perda de territórios no Oriente, ondas de peste sucessivas e a diminuição abrupta da entrada de capital na aduana de Lisboa fizeram com que a Coroa outorgasse "privilégios y mercedes a quienes pretendian descubrir y explotar minas de metales y piedras preciosas en Brasil", ${ }^{53}$ como forma de amenizar os danos financeiros de Portugal. Tal política, estimulada pelo valido Duque de Lerma, visava tornar Portugal minimamente autossuficiente, o que a autora considera "una de las líneas básicas de todas las diretivas sugeridas por Madrid en este tiempo". ${ }^{54}$

O sucesso da delegação pode ser medido pelas mercês recebidas. Segundo o próprio Manuel Juan de Morales, ele recebeu mercês de 750 cruzados e tornou-se criado do rei. Manoel Pinheiro voltou como mineiromor de todo o Estado do Brasil e fidalgo da Casa Real; e Diogo de Quadros com o direito de construir dois engenhos de ferro e a posse deles por "três vidas". ${ }^{55}$ Além disso, em seu retorno a São Paulo, Quadros trazia consigo uma carta do rei agradecendo aos moradores de São Paulo e supostamente o tal Regimento das Minas, expedido em Madri em agosto de 1603. ${ }^{56}$ Dentre os pleitos de Quadros, a questão indígena ficou na penumbra, já que ele requereu a venda, em fiado, de 2.000 escravos das Guiné aos moradores de São Paulo para a exploração e entabulamento das minas, e que the foram negados. ${ }^{57}$

52 Sobre a ida a Valladolid: ACVSP, 08/011606; 22/08/1605; AGS. SP, Libro 1463, doc. 41,42 e 110. "Informe de Manuel Juan": CORTESÃO, Jaime (org.). Jesuítas e bandeirantes no Guairá.

53 OLIVAL, Fernanda. Gobierno, crisis del período filipino. In: MILLÀN, José Martinéz; VISCEGLIA, Maria Antonieta (dir.). La monarquia de Felipe III: Ios reinos (volume IV). Madrid. Fundacion Mapfre, Instituto Cultural, 2008, p.788-789.

54 OLIVAL, Fernanda. Gobierno, crisis del período filipino, p.789.

55 AGS. SP, Libro 1463 e Parecer do Conselho de Portugal e despacho régio sobre a petição de Manoel Pinheiro Azurara. In: STELLA, Roseli Santaella. Sobre a Capitania de São Vicente, séculos XVI-XVII. São Paulo: Academia Lusíada de Ciências, Letras e Artes, 1999.

56 FRANCO, Francisco de Assis. História das minas de São Paulo.

57 ACVSP, 08 jan. 1606. Sobre os escravos da Guiné, ver pareceres do Conselho de Portugal e do Conselho da Índia sobre as petições de Diogo Quadros. Ver também: STELLA, Roseli. Sobre a Capitania de São Vicente, séculos $X V I-X V I I$. 
De fato os enviados retornaram a São Paulo somente em 1604, quando Francisco de Souza já não era mais o governador-geral das partes do Brasil. Em 1602, fora nomeado para o posto o fidalgo Diogo Botelho. Entretanto, Dom Francisco não voltou imediatamente a Portugal, como era de se esperar, permanecendo em São Paulo e imediações até 1603, época em que sua presença ainda era atestada em Atas da Câmara. ${ }^{58}$ Neste mesmo ano, Botelho enviara a São Paulo ordens para a interrupção das entradas no sertão, e dois mineiros para aferirem certas "contradições" nas minas divulgadas por Souza. ${ }^{59}$ Os dois mineiros, Juan Munhoz de Puertos e Francisco de Villalva, apesar de mandados com a missão de contradizer Souza, foram rapidamente seduzidos e convencidos por ele. Em dezembro, tinham ido conferir as minas de Monserrate, e já em 1605 acompanharam D. Francisco a Valladolid para servir de testemunhas oculares em suas petições junto ao rei. ${ }^{60} \mathrm{Na}$ verdade, o tal Francisco de Villalva aparece em documentação coeva como Francisco Villalon, conforme registro de gastos do Estado do Brasil, no qual se lê que este mineiro, Villalon, fora mandado a São Paulo, por Botelho, em fevereiro de $1602 .{ }^{61}$

O fato é que tentar compreender a capacidade aurífera das minas de São Paulo através de seus mineiros, além de tarefa inglória, pouco contribui na aferição desta riqueza. O primeiro mineiro alemão, que viera com Geraldo Betting - provavelmente Jacques Oalte -, morreu em São Paulo ainda em 1599; já sobre o segundo, enviado em 1609, existem notícias contraditórias de que teria morrido de maneira misteriosa. ${ }^{62}$ Os dois enviados por Botelho em 1602 foram cooptados por Souza. Gente especialista do Peru fora sabotada por autoridades paulistas, conforme Lourenço de Mendonça. E os nossos quatro amigos enviados a Valladolid tiveram destinos muito distintos.

Manoel Pinheiro Azurara, mineiro-mor e perito em ouro, descambou, em 1606, para o Paraguai, onde foi preso e processado por usar a via de São Paulo. Sobre ele ainda recaíram as denúncias de ter passado mais de cem escravos negros e carregar uma quantidade razoável de ouro. As suspeitas não foram comprovadas, mas o fato foi que Azurara carregou muitos tecidos e adquiriu muita erva mate no trajeto até Assunção. Entre 1609 e

58 As atas que atestam a presença de Souza: ACVSP, 22/11/1603 e 23/11/1603.

59 Eles se apresentaram à Câmara da vila em 22/08/1603. ACVSP.

60 A ida deles às minas é comprovada em ata: ACVSP, 24/12/1603. A ida à Espanha é apontada por ABREU, Capistrano de. Prolegômenos ao livro V SALVADOR, Frei Vicente do. História do Brazil (1500-1627). 7 ed. Belo Horizonte/ São Paulo: Itatiaia/Editora da Universidade de São Paulo, 1982.

61 AGS, SP, Libro 1575. Neste mesmo livro de gastos aparece Manoel Pinheiro, "mineiro de ouro das minas de San Vicente", que recebeu "quinhentos e trinta e cinco mil reis que venceu de seu ordenado a razão de cem mil reis por ano que começou a vencer em dezenove de janeiro de 1597 e acabou a 25 de maio de 1602 ". O tal Villalon ainda aparece como testemunha no testamento de Diego Martins Machuca, de 1603. Inventários \& Testamentos. V.3. São Paulo: Divisão do Arquivo do Estado de São Paulo, 1920

62 Nas atas de 11/09/1611, Baltazar Gonçalves avisa que vai ao sertão com "o alemão mineiro", por ordem de Diogo de Quadros. A despeito da proibição dos moradores irem ao sertão, os oficiais dizem que "em matéria de minas não se metiam por não ser de sua jurisdição", o que atesta a ideia da jurisdição paralela. De qualquer modo, o misterioso mineiro alemão parece ainda estar vivo depois da morte de Francisco de Souza, que ocorrera em junho daquele ano. 
1612, apareceu em processos judiciais em torno da erva em Maracayu, onde estabeleceu negócios. Do ouro ao mate, Pinheiro parecia ter uma bússola apontada para os bons negócios. Em seu processo, reclamou, diante das desconfianças gerais, que o ouro de São Paulo não era beneficiado como se deveria e que ele mesmo tinha seus salários atrasados. ${ }^{63}$

O perito em prata, Martim Rodrigues Godoy, deve ter ficado bastante decepcionado, tanto que, rapidamente, redirecionou seu alvo para Angola, pedindo mercê para explorar minas do metal naquela região. ${ }^{64}$ Diogo Quadros reclamava pelos peritos em mineração ainda em 1605 e, depois de vários entreveros em São Paulo, acabou findando seus dias na Índia. Quanto a Manuel Juan Morales (vulgo Manoel João Branco), mineiro de ferro e "espião", ele reclamava de nunca terem sido enviados os peritos solicitados, ainda insistindo na demanda em 1636, enquanto provavelmente desfrutava de sua riqueza baseada no trigo, no tráfico de escravos da Guiné e na criação e venda do gado. Sabemos que ele se tornou superintendente dos índios e administrador das minas em 1624, conforme provisão do governador-geral Diogo Furtado de Mendonça, e que vinha ainda com a inglória tarefa de remeter certa quantidade de gentios à Bahia.$^{65}$ De todo modo, em função de supostas minas descobertas nos "termos da vila de São Paulo", solicitou sesmaria, ganhando-a do capitão-mor Álvaro Luiz do Valle em 1627.66

D. Francisco, a partir de 1604, voltou à Europa e iniciou uma série de pleitos junto à corte espanhola. Apesar dos poucos resultados práticos e palpáveis que apresentava, da descrença crescente em alguns círculos reais sobre as capacidades auríferas de São Paulo, bem como das desconfianças sobre a lisura de sua atuação; o ex-governador conseguiu manter seu prestígio e suas mercês em alta junto à corte de Felipe III e de seu valido, o Duque de Lerma. Em novembro de 1607, o Duque mandou interromper a tomada de residência que se fazia sobre o governo de Francisco. ${ }^{67}$ De fato, desde dezembro de 1606 Lerma já havia decidido pela nomeação de Francisco de Souza como governador da recém-criada Repartição Sul, e capitão das minas do Brasil, que, depois de algumas dúvidas quanto à jurisdição,

63 ANA. Civil e Criminal, 1549, 4. Azurara, em seu memorial entregue em Madri, dizia que encontrara muitas minas de ouro e prata, tanto quando entrou pelo sertão com Diogo Martins Cão em 1596, quanto nas entradas com Diogo Gonçalves Lasso entre 1599 e 1601. Alegava ainda ter sido alferes de Lasso no povoamento da vila de São Felipe. AGS, SP, Libro 1463. O que pode ter causado desconfiança nas autoridades assuncenhas foi o fato de o mineiro-mor do Brasil ter ido embora pelo caminho proibido e aparentemente sem ouro. Já a alegação da falta de recebimento de salários parece ser inverídica para o período 1592 a 1602, conforme o Libro de Gastos del Brasil; AGS. Secretarias Provinciais, Libro 1575. Quanto à tença de vinte mil réis prometida pela Coroa, como mineiro-mor, só seria realizada "se as minas saíssem de tanto proveito"; AGS. Secretarias Provinciais, Libro 1463.

64 AGS. SP, Libro 1491, doc 196. Também as minas africanas decepcionaram Godoy, que finalmente voltou à carga pelo direito de chegar à Potosí com mulher e filhos em 1620. AGl, Charcas 2, 18/12/620.

65 RGCSP, 25/05/1624.

66 Instituto Nacional da Torre do Tombo (INTT). Papéis do Brasil, Códice 10, MF 695, fólio 82

67 Ordem de residência: Biblioteca D’Ajuda. Códice 51-VIII-07, f.94, 21/07/1605 e ordem de interrupção, Códice $51-\mathrm{VII}-15$, f.178, 26/11/1607. 
incluía até mesmo possíveis minas encontradas fora das três capitanias de baixo. ${ }^{68}$ Apesar das dúvidas que transparecem nas consultas ao Conselho de Portugal, ao Conselho da Índia e à Junta da Fazenda, Francisco de Souza voltou a São Paulo dotado de inúmeros instrumentos para o controle e administração, tanto das três capitanias (Rio de Janeiro, Espírito Santo e São Vicente), quanto das minas. ${ }^{69}$ Ademais, vinha com o poder de distribuir ainda mais mercês, fundamentais para formar sua rede de apoiadores e retribuir serviços e favores. Conseguia amplos poderes jurídicos de perdão a degredos e retornava com condições de dar continuidade a uma série de projetos que já havia iniciado em sua primeira passagem por São Paulo. A perspectiva de que as minas serviam como pretexto para a jurisdição sobre cargos e ofícios foi imediatamente percebida pelo governador Diego de Menezes, que, a despeito de seu rancor, suspeitava que D. Francisco "há de fazer minas a cada canto das ruas da Bahia ou de Pernambuco, quanto mais nos montes, e assim se vira a estar nelas". ${ }^{70}$ No final das contas, D. Francisco, de fato, pouco pôde fazer, já que chegou à vila em meados de 1609 e, em junho de 1611, faleceu.

Quando o governador chegou à pequena vila na primeira vez, ainda em 1599, não havia praticamente nenhum ofício que não os atrelados à Câmara. Entretanto, D. Francisco criaria, sob a jurisdição das supostas minas, um aparelho administrativo que serviu também para acomodar diversos personagens, desde gente da sua comitiva até moradores mais antigos. Instituiu, por exemplo, mamposteiro de cativos, avaliador, partidor, medidor, avaliador da fazenda, juiz dos órfãos, repartidor de terras, procurador e escrivão do campo, capitão da gente de cavalo, escrivão da ouvidoria, alferes etc.; ou seja, uma diversidade enorme de ofícios. Ainda naquele ano de 1599, os oficiais da Câmara tinham preparado uma série de demandas ao governador. De pronto, ele acenou positivamente; entretanto, os mesmos oficiais alegaram que "parecia bem não ter juiz dos índios" e que o "uso e costume" da terra era que os índios estivessem sob controle do juiz ordinário, ou seja, sob controle dos oficiais da Câmara. ${ }^{71}$ Travava-se, assim, de um primeiro embate diante de um assunto importante para qualquer projeto a ser desenvolvido em São Paulo: quem administraria a reserva de mão de obra indígena? No final o governador fez valer sua vontade e colocou a administração das aldeias indígenas na autoridade da jurisdição das minas.

68 Na carta de Menezes, nomeado governador em 1606, ele reclama desta jurisdição. CORTESÃO, Jaime. (comp.) Pauliceae Lusitana Monumenta Historica. v.I (1494-1600). Lisboa: Real Gabinete Português, 1956, p.6. Nomeação de Souza: AGS. SP, Libro 1466, 23/12/1606.

69 A desconfiança quanto a Francisco de Souza pode ser exemplificada na divisão do Conselho de Portugal, quanto à parcialidade das opiniões do ex-governador, em petição de Domingos de Araújo pelas minas da Bahia; AGS. Secretarias Provinciales, Libro 1466, f.284v. As mercês de D. Francisco estão em: AGS. SP, Libro 1466, 17/09/1607, f.298r a 310v.

70 Carta de Diogo de Menezes; CORTESÃO, Jaime. Pauliceae Lusitana Monumenta Historica, p.6.

71 ACVSP, 16/01/1599. 
Além disso, quando observamos a legislação referente ao trabalho indígena neste período, constatamos que Francisco de Souza teria sido permissivo em relação à escravização indígena. Não só fez vistas grossas ao alvará de 1595, que proibia terminantemente a escravização do índio (mesmo os capturados sob o princípio da guerra justa), como fez valer a lei de 1570, ainda do tempo de D. Sebastião, que a permitia desde que com licença direta do rei ou do governador.

É clara a conveniência da lei de 1570, pois Ihe dava ampla margem de manobra para manipular este importante mecanismo de poder e governabilidade. O governador criou uma rede de aliados, e as terras, a mão de obra indígena, os ofícios e mercês, bem como as promessas afagaram os moradores da pequena vila que foi alçada a uma condição jamais imaginada. Numa ocasião, em 1601, D. Francisco prometeu aos moradores, e fez constar do Registro Geral da Câmara, que a pequena vila de São Paulo:

Com o divino favor há de ser cidade antes de muito tempo e (seus moradores) hão de ter grandes privilégios e mercês que the eu hei de procurar com sua majestade porque foi a primeira e principal parte donde mediante o favor de Deus descobri estas minas. ${ }^{72}$

Assim, independentemente do tamanho dessa riqueza mineral, a jurisdição sobre ela rapidamente se atrelou ao descimento de indígenas e à administração das aldeias. Nesse sentido, por mais quimérica que pudesse ser a riqueza mineral, ela era ligada à palpável e disputada riqueza representada pela mão de obra indígena. Além disso, a prospecção e o beneficiamento das supostas minas passaram a ser excelentes argumentos para promover entradas ao sertão e o descimento regular de indígenas. Temas estes que começariam a incomodar a coroa de maneira crescente a partir da década de 1620, quando o assédio ao interior paraguaio mobilizou a Companhia de Jesus, bem estabelecida com suas reduções na região.

A morte do governador, em 1611, abriria a disputa por seu legado, que era composto por forte aparato legal e administrativo para gestão de alguns interesses fundamentais da Capitania, dentre eles a questão da mão de obra. Não surpreende, portanto, os interesses da família Sá na incorporação de tão ampla jurisdição, o que talvez ajude a explicar a relação tumultuada entre moradores de São Paulo e Salvador Correia de Sá e Benevides nos anos subsequentes.

72 RGCSP, 19/07/1601. Grifo meu. 


\section{Conclusão}

Parece-nos que uma quantidade de ouro razoável foi retirada das minas de São Paulo. Mais do que faiscagem, pois incluía minas, e talvez menos do que algumas notícias alardeavam. De concreto, podemos afirmar que as minas serviram para alimentar e justificar mercês - a maior parte delas concedida - de diversas autoridades, a começar pelo nosso governador, que talvez tenha percebido o potencial de cobiça que as minas despertavam na Corte para a concessão de privilégios. No mínimo aprendera com Gabriel Soares! ${ }^{73}$ Mas soa improvável que o governador tenha investido toda a sua energia somente para exercer poder e privilégios sobre uma pequena vila nos rincões da América portuguesa, se bem que o alcance regional de sua jurisdição mineral guardasse amplas possibilidades. Alguma riqueza deve ter sido vislumbrada por D. Francisco, já que fez questão de ter suas próprias minas demarcadas pelo mineiro-mor Manuel Pinheiro em Montesserrate e São Francisco.

Portanto, por mais que as minas tenham sido superestimadas, as notícias, as promessas, as possibilidades foram, de fato, criadas sobre alguma base real. Segundo Sérgio Buarque de Holanda, os paulistas se recusavam a revelar toda a verdade sobre elas porque rejeitavam o poder e a restrição à liberdade que poderiam vir com a fiscalização e administração das minas. ${ }^{74}$ Para Ruiz e Theodoro, as minas de São Paulo encobririam interesses e, ao final, concluem que elas existiriam, mas o trabalho sobre elas, não. ${ }^{75}$ Seguindo a linha de Sérgio Buarque de Holanda, estes autores acham que o fato de a capitania pertencer a donatário, não à Coroa, alimentaria certa liberdade da qual os moradores não estariam dispostos a abrir mão.

Uma parte dos moradores da vila trabalhou nas minas, extraindo delas o ouro que foi utilizado como moeda e matéria-prima de ornamentos. Pode também ter servido como capital para compra de escravos negros, tecidos e outros produtos que alimentavam relativo comércio local. Provavelmente, os moradores esconderam as reais quantidades, fugindo assim do fisco e do quinto, não raro com a conivência das autoridades, cuja maioria estava diretamente envolvida no beneficiamento das mesmas minas. Deve-se, também, cogitar a possibilidade de que parte deste ouro escoasse pelos caminhos potosinos, numa interessante troca pela prata, junto com os peruleros que usavam o caminho proibido de São Paulo, pelo Guairá, rumo aos contrafortes andinos. O mineiro Manoel Pinheiro, acusado de transportar ouro clandestino, levanta essa suspeita. Um comerciante, Miguel Moxica

73 Francisco de Souza também reivindicou o título de Marquês, usufruído verdadeiramente por seu neto, conhecido como o Marquês das Minas.

74 HOLANDA, Sérgio Buarque de. O extremo oeste. São Paulo: Brasiliense, 1986.

75 RUIZ, Rafael; THEODORO, Janice. São Paulo, de vila a cidade: a fundação, o poder público e a vida política. In: PORTA, Paula (org). História da cidade de São Paulo. v.1. São Paulo: Paz e Terra, 2004. 
Maldonado, foi preso na via proibida em 1621 com grande carregamento de tecidos e alguns escravos. Nos autos, uma questão ficaria sem resposta: alguém teria visto peças de ouro com o tal Maldonado? ${ }^{76}$

De todo modo, o "mito das abundantes minas de São Paulo" serviu, sobretudo, para construir uma trama de interesses e de poderes. Ofícios, privilégios, redes clientelares e mercês constituíam um excelente instrumento de poder sobre a capitania de São Vicente. E não só. Como as mercês sobre as minas vinham, de modo geral, acompanhadas de privilégios sobre os gentios, elas permitiam o controle e a administração da desejável mão de obra indígena. Lembremos, ainda, que as décadas de 1620 a 1640, anos nas quais as polêmicas sobre as minas mais transparecem, são um período de frequente assédio paulista às reduções do Guairá, e portanto de constante e elevado afluxo de indígenas. Nesse sentido, as disputas pelas mercês minerais e pelo exercício de influência sobre a Capitania, levados a cabo por Salvador Correia de Sá e Benevides nas décadas de 1640 a 1660, parecem se justificar. Enfim, seria pertinente afirmar que os interesses acobertados pelas minas se prestavam para construir uma jurisdição e tudo que sobre ela cabia. Mas tal demanda não se formou sobre um "castelo de areia", e, sim, sob uma "nuvem de fumaça".

76 Auto cabesa de processo contra unos portuguezes que vinieron por la via de San Pablo, camino prohibido. Año 1621. In: Bandeirantes no Paraguai. Século XVII. (Documentos Inéditos). São Paulo: Divisão do Arquivo Histórico/ Prefeitura do Município de São Paulo, 1949, p.45-66. 